
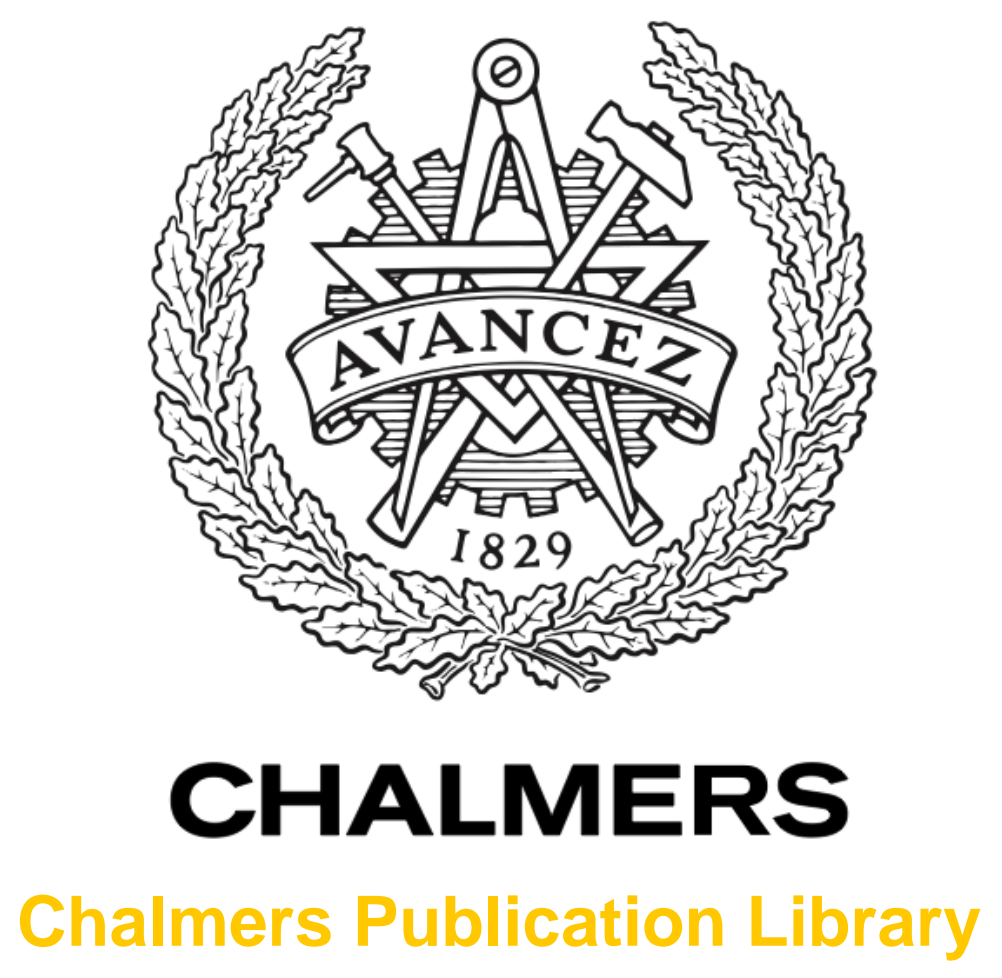

Design of an integrated dryer and conveyor belt for woody biofuels

This document has been downloaded from Chalmers Publication Library (CPL). It is the author's version of a work that was accepted for publication in:

Biomass \& Bioenergy (ISSN: 0961-9534)

Citation for the published paper:

Alamia, A. ; Ström, H. ; Thunman, H. (2015) "Design of an integrated dryer and conveyor belt for woody biofuels". Biomass \& Bioenergy, vol. 77 pp. 92-109.

http://dx.doi.org/10.1016/j.biombioe.2015.03.022

Downloaded from: http://publications.lib.chalmers.se/publication/214131

Notice: Changes introduced as a result of publishing processes such as copy-editing and formatting may not be reflected in this document. For a definitive version of this work, please refer to the published source. Please note that access to the published version might require a subscription. 


\title{
Design of an integrated dryer and conveyor belt for woody
}

\section{biofuels}

\author{
Alberto Alamia $^{1}$, Henrik Ström ${ }^{1,2, *}$, Henrik Thunman ${ }^{1}$ \\ ${ }^{1}$ Division of Energy Technology, ${ }^{2}$ Division of Fluid Dynamics \\ Chalmers University of Technology \\ *Corresponding author: henrik.strom@chalmers.se
}

\begin{abstract}
Combustion or gasification of high-moisture content biomass is associated with a number of drawbacks, such as operational instabilities and lowered total efficiency. The present work proposes an integrated dryer and conveyor belt for woody biofuels with steam as the heat transfer medium. The use of low-temperature steam is favorable from a heat management point of view, but also helps to minimize the risk of fire, self-ignition and dust explosions. Furthermore, the presented dryer design represents an efficient combination of fuel transport, drying equipment and fuel feeding system.

The proposed design is developed from a macroscopic energy and mass balance model that uses results from computational fluid dynamics (CFD) fuel bed modeling and experiments as its input. This CFD simulation setup can be further used to optimize the design with respect to bed height, steam injection temperatures and fuel type. The macroscopic model can be used to investigate the integration of the dryer within a larger biomass plant. Such a case study is also presented, where the dryer is tailored for integration within an indirect steam gasification system. It is found that the exergy efficiency of this dryer is $52.9 \%$, which is considerably higher than those of other dryers using air or steam, making the proposed drying technology a very competitive choice for operation with indirect steam gasification units.
\end{abstract}




\section{Introduction}

The use of biomass for energy production is becoming increasingly popular due to the fact that biomass is generally regarded as a $\mathrm{CO}_{2}$-neutral fuel. Wood represents a major source of biomass energy, and woody biofuels are particularly interesting in countries with large forest resources. An important difference between biofuels and most conventional fossil fuels is that the former have significantly higher and more varied moisture content.

In gasification, fuel drying is required to avoid the combustion of support fuel or product gas, to sustain the process. If the heat demand for drying can be reduced, more fuel can be gasified and the efficiency of the process is increased. Furthermore, biofuel with large fluctuations in the moisture contents causes problems with regard to the stable operation of the gasifier. Therefore in gasification systems, the fuel is usually dried to a moisture content below $15 \%$ on wet basis (w.b.) [1]. Combustion of biofuels with high moisture content is possible, but associated with several drawbacks. First of all, the latent heat that has to be supplied in the combustor to evaporate the water cannot be utilized for power generation, since the temperature at which it can be recovered is too low (i.e. around $100^{\circ} \mathrm{C}$ at atmospheric pressure). Furthermore, a boiler that is operated with high-moisture fuel must have larger dimensions for the same thermal output. In addition to operational instabilities, the additional heat sink provided by the moisture increases the risk for harmful emissions. Woody biofuels can have initial moisture contents as high as $50-65 \%$ w.b. [2, 3]. The typical heating values of dry biomass fuels are around 15-22 MJ/kg dry ash-free (daf) [4]. Low-temperature drying (below the boiling point of water) can reduce the moisture content down to 10-15\% w.b. [1]. The focus of the current work is on the design of a combined high-temperature dryer and conveyor belt for woody biofuels. More specifically, the aim is to explore the potential of high-temperature drying for large-scale processes in regions where the use of biomass has a high economic value, thus allowing for a higher level of complexity and larger investments. 
The overall purpose of this paper is thus to present a general design of an integrated dryer and conveyor belt, and calculations that support the chosen detailed dryer design. The paper includes a case study for the integration of the proposed drying system in a steam gasification plant, which represents the situation where the use of the proposed dryer is most advantageous, showing a high potential in terms of energy and exergy efficiency. The process of biomass drying and the proposed dryer are first described in Section 2. The modeling underlying the numerical simulations of the dryer performance is introduced in Section 3, and the results of these simulations are presented and discussed in Section 4. The case study for the integration of the dryer within an indirect steam gasification plant, is presented in Section 5. The paper finally concludes with a summary of the findings and a final evaluation of the dryer belt design.

\section{$2 \quad$ Biomass drying}

Woody biomass at the point of delivery is usually in the form of chips or chunks with the largest dimension in the range of 10-80 $\mathrm{mm}$ [5], and a moisture content between 50-60\% depending on the season and the type of wood. If a biomass has a lower heating value (LHV) of $19 \mathrm{MJ} / \mathrm{kg}$ and a moisture content of $50 \%$ w.b., the heat demand for the complete evaporation and heating of the moisture up to a gasification temperature of $900^{\circ} \mathrm{C}$ is about $22 \%$ of the LHV of the fuel. However, if the biomass is pre-dried to $10 \%$ w.b. moisture, the heat demand is only $2.5 \%$ of the fuel LHV. During gasification this heat is provided by combustion of the fuel or product gas. By reducing the moisture content, a higher fraction of the biomass can be gasified and the total efficiency of the process is increased. Drying is also beneficial for decreasing the dimensions of the gasifier and the ancillary equipment. 
In power generation plants, the drying of the fuel increases the efficiency of the thermal conversion of the biomass. Fuels with low moisture contents can also minimize other combustion control problems caused by fluctuations in the fuel properties [1].

Nevertheless, biomass drying is an intense process that requires a substantial input of energy, which influences the total efficiency of the process if valuable heat is used. It is therefore advantageous to use waste heat at low temperature, and to integrate the drying system within the heat exchanger network of the biomass plant. Sources of heat include heat exchanger exhaust, turbine exhaust, flue gases from combustion of by-products [1], or process steam at low temperature. Depending on the combination of the heat source and the technology employed, the drying can either be accomplished directly by heat sources such as flue gas, back-pressure steam or extraction steam [2], or via an intermediate drying medium (air or steam).

In addition to improving the efficiency of the process, the drying system should minimize the risk of fire and explosion, reduce the emissions of pollutants and ensure a homogeneous fuel feeding. A fire or explosion in the dryer can arise from the ignition of volatile organic compounds (VOC) released during the drying. Thermal degradation of the biomass starts above $100^{\circ} \mathrm{C}$ and becomes significant above $120-130^{\circ} \mathrm{C}$ depending on the type of biomass [6]. The risk of fire is, however, increased during an unintended stop of the dryer when VOCs can accumulate. The main measure to ensure a safe and reliable operation of the dryer is to maintain a sufficient inert atmosphere by continuous monitoring of the oxygen level and to install emergency safety equipment [6], especially in air and flue gas dryers. Superheated steam dyers require lower safety measures because they eliminate the risk of fire and explosion by guaranteeing an oxygen-free atmosphere around the biomass [5].

Where it is possible to maintain a low-oxygen environment in the dryer, the drying temperature can be raised to $200^{\circ} \mathrm{C}$ or above [4], which reduces the drying time and the size 
of the equipment. However, such a high temperature could produce a significant release of VOCs, which translates into an energy loss and causes environmental problems.

Several different types of biomass dryers are available, the most common are: rotary dryers [7][8], fluidized bed dryers (including flash dryers and superheated steam dryers) [4] and belt dryers [4].

Belt dryer is the typology better suited to exploit low-temperature heat $\left(130^{\circ} \mathrm{C}\right.$ or lower), limiting the risk of fire, harmful emissions and in some case allowing heat recovery from the dryer. Biomass is disposed on a permeable belt (e.g. a perforated conveyor or filter mesh/mat), and transported along the dryer while the drying medium is blown by fans through the belt and the biomass bed. The height of the biomass bed is typically between $2 \mathrm{~cm}$ and 30 $\mathrm{cm}$, depending on the type of biomass. Due to the low temperature used, these dryers have long retention times and consequently require large installations. Typical temperatures of the drying medium are between $60^{\circ} \mathrm{C}$ and $200^{\circ} \mathrm{C}$. They are safe to operate, minimizing the risk of fire and explosion, and produce low emissions of VOCs. This type of dryer is suitable to recover waste heat, reduce the emissions of pollutants and minimize fire hazards. It is now used in many applications (e.g. sawdust drying in pellet production).

\subsection{Proposed drying system}

The proposed drying system is intended mainly for gasification, but can be applied to biomass combustors as well. The dryer process design is based on the concept of a conventional belt dryer and the operation of the dryer is continuous. Known advantages of belt dryers include low operation temperature, low gaseous emissions, low fire hazards, high robustness with regard to varying fuel properties and high potential for heat recovery [4].

The drying system, depicted in Figure 1, consists of two consecutive belt dryers with a possibility of intermediate storage. The first stage uses a conventional belt dryer that employs low-temperature heat sources (below $100^{\circ} \mathrm{C}$ ) and air as the drying medium. Drying can 
typically be extended from an initial $50 \%$ to $10-20 \%$ moisture in the fuel by using only waste heat from the rest of the plant. A following drying stage at a higher temperature $\left(120-150^{\circ} \mathrm{C}\right)$ can reduce the moisture content down to a few percent. In this work, a belt dryer using steam as the drying medium is proposed for this drying stage. Steam allows a higher drying temperature virtually without any risk of fire and, furthermore, it allows discharging the fuel directly into the charge hopper of the feeding system, maintaining the biomass in a steam atmosphere. This is especially intended for production of nitrogen-free gas, since the fuel is introduced into the reactor without the contamination that would occur if flue gases were used as the purge gas in the sealing device (e.g. lock hoppers or rotary valves) [1].

There are three major motivations to why the proposed dryer design is very competitive:

1) Minimization of the risk of self-ignition or dust explosions

Typically, interim storage of woody biofuels takes place below the fiber saturation point, i.e. at a moisture content of approximately $18-20 \%$ w.b. [3]. Higher moisture contents may allow bacterial growth with subsequent production of inflammable gases. In addition, microbial activity such as fungal growth is known to cause a slow heat development that may subsequently accelerate further heat release, which could lead to self-ignition [9], [10]. Microfungi can also cause allergic reactions in people handling the biofuel [9]. Moisture contents significantly lower than $18 \%$ w.b. are known to increase the risk for dust explosions, as dust clouds may be ignited if oxygen is present [3]. The risk of explosion or ignition increases with temperature, and biofuel devolatilization begins at relatively low temperatures. The proposed dryer and conveyor belt design utilizes pure steam between $120^{\circ} \mathrm{C}$ and $150^{\circ} \mathrm{C}$ as the heat transfer medium. The risk of spontaneous ignition is efficiently counteracted, since the steam atmosphere contains virtually no oxygen. 
Because of the fire hazard associated with the storage of biofuel, the particles must be stored well away $(50-300 \mathrm{~m})$ from the gasifier. A long conveyer belt is thus needed to transport the particles to the combustor. With the proposed dryer design, this distance is efficiently utilized, as the transportation time is used to decrease the moisture content of the particles. Furthermore the biomass is pre-heated and delivered to the feeding system in a steam atmosphere, avoiding nitrogen contaminations.

\section{Efficient heat management}

As the drying of the biofuel represents a significant part of the combustor system energy utilization, efficient energy management is of utmost importance. Low-pressure steam is readily available in combustion plants and represents a suitable choice from the heat management perspective. The steam can, for example, be generated from a combination of low-grade heat available in hot cooling water and flue gases [4].

The proposed design of the integrated steam dryer and conveyor belt is illustrated in Figure 2. The biomass is transported on a mechanical belt along the drying unit, while superheated steam is injected from above, drying the particles by supplying the energy needed for water evaporation. Furthermore, the steam will help remove part of the dust formed in the handling of the biomass, and this dust will be collected on the belt as the steam passes through it. In this respect, the belt acts as a filter for the dust particles. The dust can then be scraped off from the belt at the end of the conveyor section.

The steam that has passed through the bed is led via a three-way valve to a fan and a heat exchanger. The valve is regulated to remove the flow of moisture evaporated, and maintain the mass balance of the steam within the dryer. The fan and the steam heat exchangers are designed to restore the steam flow pressure and temperature to the injection conditions. 
Air or flue gases can be used to purge the biomass into the dryer; they are evacuated at the beginning of the belt together with some steam. Therefore some water is fed in to maintain the steam balance in the first part of the dryer where any moisture is evaporated.

As the biofuel storage site and the combustor are typically separated by long distances, the conveyor belt as depicted in Figure 2 would necessarily also be long. However, an alternate, module-based design could be conceived, in which the total length of the conveyor belt is split into smaller sections. This variation of the original design has several advantages: 1) the injection temperature of the steam can easily be varied along the dryer; 2) the packing of the bed of biofuel can be adjusted, by varying the height and velocity of the different belt sections; 3) additional locations for dust removal are introduced.

\subsection{Potential for integration within an indirect steam gasification system}

Although the proposed belt dryer offers the possibility of heat integration through indirect heating and recirculation of the drying medium, the enthalpy stored in the evaporated moisture leaving the dryer cannot be recovered by any other means than condensation. If the dryer is integrated with a plant using steam in processes directly involving the biomass, the moisture evaporated can be then re-used without condensing and the potential for heat recovery is significantly increased. The integration of the steam belt dryer within a biomass gasification plant, using steam as the gasification agent, has been investigated further in a case study, since it introduces additional advantages and can be beneficial for the whole process. In indirect gasification, pre-heating of the streams entering the gasifier (fuel and gasification/fluidization steam) is beneficial for the heat balance of the gasifier-combustor system. Reducing the heat demand of the gasifier can increase the yield of product gas since less fuel needs to be burnt in the combustor. Shifting of fuel drying and pre-heating outside of the gasifier also enables low-temperature heat to be used instead of high-temperature heat from fuel combustion. The temperature in the last part of the dryer can be raised to pre-heat 
the fuel to $105^{\circ} \mathrm{C}-140^{\circ} \mathrm{C}$. However, the highest temperature in the biomass bed should not be higher than $200^{\circ} \mathrm{C}$ [11] in order to avoid significant devolatilization of the biomass. Furthermore, the moisture evaporated along the dryer is recycled to the gasifier and used as a gasification agent, reintroducing the moisture into the mass balance of the system and reducing the steam consumption. In a steam dryer, the moisture content can be lowered from $20 \%$ w.b. to around $2 \%$ w.b., leading to a ratio between the removed moisture and the dry biomass of around 0.23 . The steam-to-fuel (dry ash free) ratio for gasification and fluidization in a bubbling bed reactor is in the range of $0.5-1$ [12]. Therefore, a significant part of the gasification steam can be substituted using the moisture, which contains some fraction of volatiles components as well.

Indirect gasification technology has the advantage of producing nitrogen-free gas by using steam as gasification agent. At current state of the art, the biomass is purged in the gasifier by using carbon dioxide, if available, or flue gas, allowing a small fraction of nitrogen in the product. Both carbon dioxide and flue gas introduce contaminations into the product gas and these have to be removed later in the fuel synthesis process, which is expensive. Therefore, for this type of gasifier, the optimal choice for biomass pre-heating and purging is steam. By combining the dryer and feeding system, it is possible to achieve efficient drying in an inert atmosphere, pre-heat the biomass and part of the gasification steam, and purge the fuel without contamination.

\section{$3 \quad$ Modeling}

Macroscopic modeling of the dryer based only on global heat and mass balance cannot be accurate, because the correct combination of the steam flow and the steam temperature cannot be found a priori, without considering the fluid dynamics in the dryer. A multi-scale modeling approach is used instead to evaluate the viability of the proposed dryer design. On 
the macroscale, the entire dryer is simulated using macroscopic heat and mass balances. Information about the drying process for a two-dimensional cut of the steam flow through the packed bed of wood particles is obtained from computational fluid dynamics (CFD) simulations. In these CFD simulations, the evolution of the drying front inside an individual particle is modeled using a particle submodel. The results from the CFD simulations are used in the macroscopic description of the dryer to enhance the numerical predictions of the capacity of the dryer.

The minimum temperature of the steam leaving the belt must be limited to avoid steam condensation. Here, the minimum steam temperature allowed along the dryer is $105^{\circ} \mathrm{C}$. Furthermore, the highest temperature inside the biomass particle should be monitored to control the release of volatiles. To maintain the steam and the biomass temperatures within an appropriate range, the biomass bed height and the steam injection temperature are varied along the dryer.

The dryer is divided in two sections. In the first section the biomass is heated to around $100^{\circ} \mathrm{C}$, with minimal moisture evaporation. To prevent steam condensation in the first section, the steam injection temperature is higher than in the rest of the dryer and steam flow per kg of biomass is increased by lowering the height of the biomass on the belt. Most of the moisture is evaporated in the second section of the dryer, where the bed height and the steam injection temperature are adjusted to limit the temperature of the dry biomass to reduce the VOC emissions. This approach is applied both in the macroscopic model and in the CFD simulation. Steam diffusion along the belt is neglected and the steam mass balance is calculated independently in the two sections.

\subsection{Thermodynamics of moisture desorption}

Moisture in wood exists in two basic forms: liquid free water in the wood cavities and bound water sorbed within the wood cell walls. In studies of wood drying, it is necessary to take into 
account the thermodynamic effects associated with the desorption of the bound moisture. When the wood and the surrounding atmosphere are in equilibrium, the relative humidity within the wood cells and the surroundings are the same. In a desorption process, free water is first evaporated until the wood reaches the fiber saturation point, then any additional moisture is desorbed from the fibers. The sorption isotherm curves describe the relation between the moisture content and the activity of the wood (ratio of partial pressure to vapor saturation pressure) at equilibrium for a given temperature. There exist many expressions of the sorption isotherm curves in the literature that descend from different sorption theories (e.g. the Dent equation, the BET equation and the Hailwood-Horrobin equation [13]) and that make use of numerical constants dependent on the type of wood and the sorption temperature. However, these equations are usually evaluated in the range between $20^{\circ} \mathrm{C}$ and $70^{\circ} \mathrm{C}$. Due to the higher temperature range in this work, average sorption curves from experimental data up to $100^{\circ} \mathrm{C}$ have been used instead (Appendix C, Figure C.2). These curves are derived from the USDA forest service database and are representative of several types of wood [14]. Sorbed water has lower vapor pressure than free water, therefore the enthalpy, entropy and Gibbs free energy of sorbed water are lower than those of water in liquid form [13]. The enthalpy $H_{s}$ of the sorbed water is lower than $H_{w}$ (saturated liquid water) by the differential term $\Delta H_{s}$, corresponding to the heat of sorption that should be provided, in addition to the evaporation heat for the phase change of the sorbed water.

$H_{s}=H_{w}-\Delta H_{s}$

$\Delta H_{s}$ is a strong function of the moisture content of the wood and is zero at the fiber saturation point. The heat of sorption can be expressed through the Clausius-Clapeyron equation [13]:

$\Delta H_{s} \cong R T^{2} \cdot\left(\mathrm{d} \ln \left(a_{w}\right) / \mathrm{d}(T)\right)$

Where $R$ is the gas constant and $a_{w}$ is the activity of the wood. As shown from the sorption isotherm curves (in Appendix C), $a_{w}$ is more dependent on the moisture content than on the 
temperature, and the same is valid for the heat of sorption. Therefore, if two sorption isotherms are known, $\Delta H_{s}$ can be estimated (assuming it to be constant between the two temperatures) by:

$\Delta H_{s} \cong R T_{1} T_{2} \cdot \ln \left(a_{w 2} / a_{w 1}\right) /\left(T_{2}-T_{1}\right)$

The entropy of the sorbed water is given by [13]:

$S_{s}=S_{w}-\Delta H_{s} /_{T}+\Delta G_{s} /_{T}=S_{w}-\Delta S_{s}$

The decrease of free energy associated with the sorption of water by a hygroscopic material is given by:

$\Delta G_{s}=-R T \ln \left(a_{w}\right)$

Enthalpy and entropy of sorbed water are strictly dependent on the activity, which is directly linked to the moisture content, of the wood. The enthalpy, $H_{s}$, and entropy, $S_{s}$, of sorbed water decreases with the decreasing moisture content, for all temperatures, and are significantly lower than those of free water at low moisture contents [13]. The preceding relations are used to account for the heat of sorption in the current work.

\subsection{Macroscopic framework}

The macroscopic heat and mass balances are formulated and solved using the commercial process modeling software Aspen Plus V8.2. Biomass can be modeled in Aspen Plus as a non-conventional component specifying ultimate and proximate analysis, including the moisture content. This approach introduces an error in the calculation of the enthalpy, due to the difference in the specific heat capacity of coal and biomass. In this work, the heat load of the dryer is calculated from the CFD results, where the specific heat capacity of dry wood is temperature dependent and is represented by an empirical correlation from the literature [10] based on data collected up to $450 \mathrm{~K}$ :

$$
C_{p, \text { wood }}[\mathrm{J} / \mathrm{kgK}]=4.206 \cdot T(K)-37.7
$$


The moist wood has a greater specific heat capacity than what would be expected from a simple law of mixtures, due to the energy absorbed in the wood-water bounds [15]. Here, this effect is taken into account via a correction term, $A$ :

$C_{p, \text { moist }}[J / k g K]=\frac{C_{p, \text { wood }}+4190 \cdot Y_{\text {moist }} /\left(1-Y_{\text {moist }}\right)}{1+Y_{\text {moist }} /\left(1-Y_{\text {moist }}\right)}+A$

$A=\left(23.55 \cdot T-1320 \cdot Y_{\text {moist }}-6191\right) \cdot Y_{\text {moist }}$

In Equations (7) [10], and (8) [15], $Y_{\text {moist }}$ is the moisture content of the moist wood on wet basis.

The necessary inputs to the macroscopic mass and heat balances include the temperature history of the biomass particles and the steam, as well as the evolution of the particle moisture content with time. These inputs are obtained from the CFD calculations. The results from the Aspen Plus model can then be used for the design of the steam heat exchangers and the fans, offering a complete assessment of the drying technology.

The Aspen Plus flow-sheet is reported in Figure 3. It is divided in two sections, modeled with a structure similar to a flow-sheet for coal drying [16], but with the addition of the steam/moisture circuit. Heat transfer between the injected steam and the biomass is accounted in the block "INT-HE", while the temperature of the circulated steam is restored in the "HE" blocks corresponding to the actual heat exchanging units.

At the end of the belt, part of the steam is trapped in the rotary valve together with the biomass. It has been assumed that $40 \%$ of the volume in the rotary valve is occupied by the biomass; the resulting steam flow leaving the dryer in this way is about $5 \%$ of the moisture generated. It is worth noticing that, since the amount of steam used as purge gas is considerably lower than the moisture evaporated, in the overall mass balance the biomass is purged into the gasifier by the use of its own moisture. The rotary valve is modeled with the two blocks "WHEEL-1" and "WHEEL-2", where part of the injected steam is first separated from the main flow and then mixed with the biomass leaving the dryer. 
The heat load of the two heat exchangers "INT-HE-1" and "INT-HE-2" (simulating the heat exchange between the steam and the biomass) and the steam flow passing through them, as well as the moisture contents at the outlet of each drying section, are set by the results from the CFD simulation. The pressure drops on the steam side of the heat exchangers can be freely chosen by the designer to achieve the lowest operating cost, taking into account both investment costs and pumping costs. In this investigation, the pressure drop has been estimated as a fraction of the system gauge pressure as suggested in [17] for tube and shell heat exchangers, placing the steam on the tube side.

The mass balance in the two sections of the dryer is maintained by a three-way valve controlling the amount of steam discharged. This stream is condensate and the heat can be recovered in the previous air dryer.

\subsection{CFD framework}

CFD simulations are performed in two dimensions using the commercial CFD software ANSYS Fluent 13.0 with a particle submodel (described in Section 3.4) supplying source terms to the Eulerian momentum, heat and mass balance equations. The computational domain represents a cut through the dryer, perpendicular to the main transport direction, and is illustrated in Figure 4. The particle submodel is active in the biomass bed region. The pressure drop from the steam inflow to the steam outflow is specified as a boundary condition, and symmetry boundary conditions are used along the vertical sides. The pressure drop over the biomass bed is determined from source terms in the momentum balance equations in this region [18]. The pressure drop over the dryer belt is tuned by manually adjusting a source term in the same equations in this region.

The CFD simulation is advanced in time while the biomass temperature and moisture content plus the steam outflow temperature are being monitored. The bed height in the first section of the dryer is $0.1 \mathrm{~m}$. The first section ends and the second section commences when the 
temperature of the hottest dry biomass reaches $105^{\circ} \mathrm{C}$. The biomass bed is then redistributed onto another belt, so that the bed height changes to $0.2 \mathrm{~m}$. These bed heights can be considered typical for conveyor dryers [4]. A number of variables need to be mapped from the $0.1 \mathrm{~m}$ solution to the initial state of a $0.2 \mathrm{~m}$ bed for continued drying at a lower steam temperature. The profiles of these variables through the bed are exported from the solution at a point in time just before the switch. These profiles are then extended to cover a bed of twice the height and prescribed as the initial condition for the remainder of the simulation. The steam injection temperature is set to $120^{\circ} \mathrm{C}$ at the domain inlet at the time of the switch. In reality, the height of the cover above the conveyor belt determines the injection point for the steam flow. In the present analysis, however, the steam inflow boundary condition is placed at a lower vertical position, where it is reasonable to assume a constant pressure profile.

\subsection{Biomass particle drying model}

Drying of the biomass particle is modeled using a two-layer sharp interface model, in which it is assumed that the heat transferred to the particle is conducted from the particle surface to a drying front where the drying takes place [19]. The drying front moves with time further into the particle, until the drying is complete and all water has been evaporated.

In the model, the particle is defined as containing two layers of a certain mass of moist wood $\left(m_{m o i s t}\right)$ and of dry wood $\left(m_{d r y}\right)$. The mass fractions of the two respective layers always add up to unity. Furthermore, the moist and the dry wood are assigned individual temperatures $\left(T_{\text {moist }}\right)$ and $\left(T_{d r y}\right)$. The evolution of the mass and temperature of each layer can then be determined from the following heat and mass balances:

$$
\begin{aligned}
& \frac{d T_{d r y}}{d t}=\frac{\alpha_{d r y}}{V_{d r y}}\left(\left.A_{s} \frac{d T}{d r}\right|_{S}-\left.A_{i} \frac{d T}{d r}\right|_{d r y \rightarrow i}\right) \\
& \frac{d T_{\text {moist }}}{d t}=\left.\frac{\alpha_{\text {moist }}}{V_{\text {moist }}}\left(1-F_{i}\right) A_{i} \frac{d T}{d r}\right|_{i \rightarrow \text { moist }} \\
& \frac{d m_{d r y}}{d t}=R_{\text {drying }} / Y_{m, d b}
\end{aligned}
$$


$\frac{d m_{\text {moist }}}{d t}=-R_{\text {drying }} / Y_{m}$

Here, $\alpha_{d r y}$ is the thermal diffusivity of the dry wood layer, $A_{s}$ is the particle surface area and $A_{i}$ is the surface area of the interface at which the drying front is currently located. $V_{d r y}$ and $V_{\text {moist }}$ are the volumes of the dry wood and the moist wood respectively, $R_{\text {drying }}$ is the rate of drying, and $Y_{m}$ and $Y_{m, d b}$ are the fuel moisture fractions on wet and dry basis respectively.

Assuming the particles are of spherical shape, the surface areas are given by:

$A_{s}=4 \pi r_{p}^{2}$

$A_{i}=4 \pi r_{d r y i n g}^{2}$

Here, $r_{p}$ is the particle radius and $r_{\text {drying }}$ is the current position of the drying front. The radial positions of the center of mass of the moist and the dry wood layers are denoted as $r_{\text {moist }}$ and $r_{d r y}$, respectively.

The temperature gradients in the vicinity of the surface and the drying front are calculated based on the assumption that the temperature field resembles the steady-state conduction profile in a spherical shell:

$\left.\frac{d T}{d r}\right|_{s}=\frac{T_{p}-T_{d r y}}{r_{p}\left(\frac{r_{p}}{r_{d r y}}-1\right)}$

$\left.\frac{d T}{d r}\right|_{d r y \rightarrow i}=\frac{T_{d r y i n g}-T_{d r y}}{r_{d r y i n g}\left(\frac{r_{d r y i n g}}{r_{d r y}}-1\right)}$

$\left.\frac{d T}{d r}\right|_{i \rightarrow \text { moist }}=\frac{T_{\text {drying }}-T_{\text {moist }}}{r_{\text {drying }}\left(\frac{r_{\text {drying }}}{r_{\text {moist }}}-1\right)}$

There are several different methods available of determining the drying rate [26]. During lowtemperature drying, a significant portion of the moisture may leave the particle at temperatures below the boiling point. Such effects cannot be captured by thermal models, in which the drying is modeled as taking place at a constant temperature. In the current work, we therefore use the modified thermal model of Ström and Thunman [19], where some 
evaporation is allowed also during the heat-up phase. The function $F_{i}$ is an empirical function on the interval $[0,1]$ that determines the portion of the heat transferred to the drying front used in the evaporation of water (the rest is used to heat the moist wood):

$F_{i}=\frac{\left.10^{\left(8.07131-1730.63 /\left(T_{\text {drying }}-39.724\right)\right.}\right)}{760}$

The rate of drying is obtained from:

$R_{\text {drying }}=\frac{\left.F_{i} k_{d r y} A_{i} \frac{d T}{d r}\right|_{d r y \rightarrow i}}{\Delta H_{\text {vap }, H_{2}} O\left(T_{\text {drying }}\right)}$

Here, $\Delta H_{\text {vap,H2O }}\left(T_{\text {drying }}\right)$ is the heat of evaporation of water, including the heat of sorption, at the temperature of the drying front, and $k_{d r y}$ is the thermal conductivity of the dry wood. Further discussion about this modeling approach is presented in Section 3.6.

In order to close the set of equations, expressions for the temperature of the particle surface $\left(T_{p}\right)$ and the temperature of the drying front $\left(T_{\text {drying }}\right)$ are needed. These are obtained from heat balances over the particle surface and the drying front, which are derived based on the assumption that no heat is accumulated at these boundaries:

$$
\begin{aligned}
& h A_{s}\left(T_{g}-T_{p}\right)-\left.k_{d r y} A_{s} \frac{d T}{d r}\right|_{s}=0 \\
& \left.k_{d r y} A_{i} \frac{d T}{d r}\right|_{d r y \rightarrow i}-\left.k_{m o i s t} A_{i} \frac{d T}{d r}\right|_{i \rightarrow m o i s t}=0
\end{aligned}
$$

In addition, the temperature of the drying front is not allowed to exceed $105^{\circ} \mathrm{C}$.

The initial conditions are:

$$
\begin{array}{r}
\frac{m_{m o i s t}}{m_{d r y}+m_{m o i s t}}=1 \\
\frac{m_{d r y}}{m_{d r y}+m_{m o i s t}}=0
\end{array}
$$


The initial moisture content is $10 \%$ (on dry basis) and the initial particle radius is $10 \mathrm{~mm}$. Material data is taken for beech wood from the literature [27] [28] [29]. The performance of the particle submodel has previously been validated against experimental data in terms of both particle mass loss and the internal particle temperature history [19]. The application of this class of bed models to the drying process in stationary and moving packed beds are known to yield very good agreement with the available experimental data [30] [31] [32], and the qualitative behavior of the in-bed temperatures from the present model setup agrees with the experimental observations of Lerman and Wennberg [33]. Finally, the chosen spatial and temporal resolution for the bed simulations in this work were evaluated and deemed adequate in detailed convergence tests. With the resolutions employed ( $\Delta t=5 \mathrm{~ms}$ and $\Delta x=2 \mathrm{~mm}$ ), estimates of the integrated deviation from the solution obtained with a finer resolution (an order of magnitude smaller time step or halved grid spacing) were as low as 110 and $64 \mathrm{ppm}$, respectively, indicating that the resolutions employed can be trusted to provide numerically converged results. Coarser resolutions (an order of magnitude larger time step or doubled grid spacing) produced deviations of $0.074 \%$ and $17 \%$, respectively. These estimations of the total integrated deviation were obtained by explicit calculation of the deviations for one minute of real time and then scaling them up to a total time period of 60 minutes.

\subsection{Mass transfer effects}

Since the water evaporates in an environment consisting purely of steam, there is no net mass transfer from the drying front to the bulk of the dryer. It would then appear as if the drying rate is controlled only by the heat transfer to the drying front. However, the outflow of water vapor from the drying front via the particle pore network out to the steam bulk will impede the heat transfer to the particle surface and thus affect the rate of drying. To account for this effect, the correlation for the particle Nusselt number [20]: 


$$
N u=2+1.1 \operatorname{Re}^{0.6} \operatorname{Pr}^{0.33}
$$

is adjusted according to:

$$
\frac{h}{h_{0}}=\frac{\rho_{g} u_{g} c_{p, g} / h_{0}}{\exp \left[\rho_{g} u_{g} c_{p, g} / h_{0}\right]-1}
$$

Where $h_{0}$ is the convective heat transfer coefficient obtained from equation (25) via the Nusselt number, and $h$ obtained from equation (26) is finally used in equation (20).

\subsection{Water evaporation temperature}

In the particle submodel described in Section 3.4, the water is assumed to evaporate from the biomass particle at a temperature of $105^{\circ} \mathrm{C}$ or below. There are two good reasons for choosing this approach.

First, the definition of moisture according to the current Swedish standard is the amount of water evaporated after 24 hours at $105^{\circ} \mathrm{C}$ [21]. In other words, any additional - more tightly bound - water in the wood matrix that leaves at higher temperatures is by definition not included in the moisture content by which the biomass is classified.

Second, the assumption that the water leaves at temperatures equal to or lower than $105^{\circ} \mathrm{C}$ is clearly supported by experimental investigations. The normalized weight loss and temperature of 19 samples of wood chips were recorded during temperature-programmed evaporation in a thermogravimetric analysis (TGA), (Appendix A, Figure A.1). The wood chip samples are first heated to $105^{\circ} \mathrm{C}$ and held at this temperature until the drying is complete (the weight loss curve levels off). After this period, the temperature is increased to $160^{\circ} \mathrm{C}$ and held constant for an hour. No significant additional weight loss is observed during this time at a higher temperature. The conclusion is that the amount of more tightly bound water is insignificant compared to the total moisture content of the wood chips. In addition, this experiment proves that the devolatilization of the wood chips is slow enough, even at $160^{\circ} \mathrm{C}$, to be neglected in the dryer simulations. 
Finally, it can also be seen in the experimental results that approximately $20 \%$ of the initial moisture has evaporated before $105^{\circ} \mathrm{C}$, which further supports the decision to use the modified thermal model for the determination of the drying rate (equation (18)).

\section{Standalone dryer design - results and discussion}

CFD simulations were performed with steam temperatures of $120^{\circ} \mathrm{C}$ and $150^{\circ} \mathrm{C}$ and biomass bed heights of $0.1 \mathrm{~m}, 0.2 \mathrm{~m}$ and $0.3 \mathrm{~m}$. The results showed that high steam temperature $\left(150^{\circ} \mathrm{C}\right)$ and low bed height $(0.1 \mathrm{~m})$ are necessary to avoid steam condensation in the first section of the dryer. Most of the drying occurs in the second section, which has a higher biomass bed and a lower steam temperature $\left(120^{\circ} \mathrm{C}\right)$ instead.

The bed height can be increased inside the dryer by moving the biomass on a narrower belt or onto a belt with a lower speed. In the CFD model, the steam temperature and the bed height are switched when the highest surface temperature of the biomass particles reaches $105^{\circ} \mathrm{C}$, determining the residence time in the section. The temperature profile results, from the CFD simulation, are presented in Figure 5, and the temporal evolution of the biomass moisture contents is shown in Figure 6.

The residence time in the first section of the dryer is $393 \mathrm{~s}$, and $2.55 \mathrm{~kg}$ of steam at $150^{\circ} \mathrm{C}$ are used per kg of dry biomass. The wood chips leave the first section with a moisture content of 9.6\% w.b. and an average bed temperature of $101^{\circ} \mathrm{C}$. The demand for heat in the first section is $151 \mathrm{~kJ} / \mathrm{kg}$ biomass (daf). The results of the complete run are presented in Table 2 for different values of the final moisture contents.

In the particle submodel employed in the CFD simulations, it is assumed that most of the moisture evaporates at $105^{\circ} \mathrm{C}$. In reality, some water will already leave at a lower temperature. When the drying temperature is lower than $105^{\circ} \mathrm{C}$, the driving force for the heat transfer is larger than assumed in the present calculations. Consequently, the results presented here represent an overestimation of the time needed to dry the wood particles. 


\subsection{Dryer design and heat losses}

The combination of CFD simulation and macroscopic modeling offers a fairly simple tool to assess the proposed dryer design. A scale of $100 \mathrm{MW}$ fuel input, corresponding to $5.4 \mathrm{~kg} / \mathrm{s}$ of dry ash-free biomass, is used as a reference for the design and macroscopic modeling.

The dimensions of the dryer can be estimated from the residence time and the length of the conveyor. If the belt width is constant in all sections, the belt speed in each can be considered inversely proportional to the bed height, and therefore the belt speed in the first section is double than in the second.

speed belt sect. $2=\frac{\text { Ltot }}{\tau_{1} \frac{h_{\text {bed } 2}}{h_{\text {bed } 1}}+\tau_{2}}$

belt width $=\frac{{\text { mass } \text { flow }_{\text {dryer }}}_{\text {mass }_{C F D}}}{h_{\text {bed2 } 2} \cdot \text { speed belt }_{\text {sect. } 2}}$

In biomass plants, the length of the conveyor from the fuel storage to the gasifier is usually between 50 and $300 \mathrm{~m}$, depending on the logistics of the plant and on safety regulations. Air belt dryers have typical belt width values in the range $0.5 \mathrm{~m}$ to $2.5 \mathrm{~m}$ [22] and a belt speed between $2 \mathrm{~cm} / \mathrm{s}$ and $10 \mathrm{~cm} / \mathrm{s}$.

Heat losses along the dryer are assuming that the dryer is a cylinder in stainless steel of $175 \mathrm{~m}$ in length and a diameter corresponding to the belt width of $1.65 \mathrm{~m}$, insulated with a layer of polyurethane foam with a thickness of $30 \mathrm{~cm}$. The convective heat transfer coefficient with the surroundings is assumed to be $7.5 \mathrm{~W} / \mathrm{m}^{2} \mathrm{~K}$ and the external temperature is $20^{\circ} \mathrm{C}$. The losses are included in the inputs for the macroscopic model, which are presented in Table 4.

The results of the heat and mass balance for a $100 \mathrm{MW}$ (fuel input) plant are reported in Table 5. The heat load of the two heat exchangers is calculated together with the mass flows and the electricity consumptions of the fans.

The heat demand is almost evenly distributed between the two heat exchangers, despite that they handle different mass flows of steam. The low temperature difference of the steam in the 
second section of the dryer leads to a mass flow considerably larger than in the first section. This is strictly dependent on the steam injection temperature used and can be optimized further.

The macroscopic model results agree well with the literature in regard to the heat consumption of an air belt dryer [5]: the average value of the proposed design is about 6.57 $\mathrm{MJ} / \mathrm{kg}_{\mathrm{H} 2 \mathrm{O}}$, including the pre-heating of the biomass up to $110^{\circ} \mathrm{C}$.

The results of the model do not aim to provide a final design for the dryer, but to assess the viability of this technology. Therefore, the calculations are not optimized for the best dryer design. However, the results show good agreement with typical values for air belt dryers, and the dimensions of the dryer and the belt speed fall into the usual range for this drying technology. The proposed dryer/carrier could therefore be designed from the retrofit of an existing air belt dryer. The effect of parameters like bed height or steam injection temperatures can be investigated further for a specific biomass plant. The proposed modeling approach provides a tool for preliminary design of a real dryer, or for assessment of the dryer performance in the modeling of a larger process.

\subsection{Additional design considerations}

Emissions have been reported to be low at temperatures below $100^{\circ} \mathrm{C}$ [15], so the operation of the dryer as proposed here should produce very low levels of emissions in the condensates. The types of emissions that can be expected include biological organisms, organic compounds and non-condensable light gases [5]. Because the use of steam as the heat transfer medium may cause problems with corrosion, the dryer will have to be manufactured in stainless steel, or the internal surface should be extensively coated. It is therefore estimated that the capital investment of building the dryer will be significantly (approximately a factor of 1.5-3) higher compared to a similar construction in carbon steel [5]. 


\section{gasification system}

Combining the dryer with the feeding system of an indirect steam gasifier, it is possible to achieve efficient drying in an inert atmosphere, pre-heating of the biomass and part of the gasification steam, and purging of the fuel without contamination. The layout of the integration of a steam belt dryer into an indirect gasification plant is depicted in Figure 7. In this case, the initial moisture content of the biomass is $20 \%$ w.b., this being the minimum value allowed for the interim storage of the biomass.

Medium pressure (MP) steam at 7 bars and low pressure (LP) steam at 3.6 bars are used to provide heat for the dryer, condensing at $165^{\circ} \mathrm{C}$ and $140^{\circ} \mathrm{C}$. The steam condensers can be integrated in an existing steam cycle, recovering heat from the flue gases out of the combustor and the cooling of the product gas. The hot water out of the condenser can be further used in the air dryer or for district heating.

The dryer is designed in three sections, the first two are analogous to those presented previously, while the third section is intended to preheat the biomass to around $130^{\circ} \mathrm{C}$ and remove the remaining moisture. In the last part of the dryer, some volatiles will be released and mixed with the steam while a part of them will be recovered in the gasifier together with the moisture. Although some odor due to the VOC will possibly be detectable, the experiments performed on wood chips (Appendix A, Figure A.1) show that the mass of volatiles released at $150^{\circ} \mathrm{C}$ it still very low, thus this temperature level can be allowed at the end of the dryer. Most of the drying occurs in the second section, with steam at $130^{\circ} \mathrm{C}$. The three-way valve expelling the moisture evaporated from the second section is connected to the inlet of the condenser in the third section, so that all moisture removed is mixed and heated to $155^{\circ} \mathrm{C}$. Another three-way valve is placed after the condenser in the third section to retain the steam balance of the system by extracting the moisture evaporated, which is then mixed with 
the rest of the gasification steam. The combustion of char in the boiler usually leads to high emission of carbon monoxide related to the low concentration of water in the flue gases. Part of the moist air coming from the air dryer can be used in the combustor to increase the water concentration and control carbon monoxide emissions. 5.1 Exergy analysis

There is no general agreement over the definition for second-law efficiency. However, it is often referred to as the ratio of the recovered exergy to the exergy supplied. This definition applies well enough to systems intended to produce or consume work, but for a drying system the meaning of the exergy recovered from the system is debatable. Instead, the second-law efficiency can be better expressed as the ratio of the minimal exergy that must be invested in the process to the exergy that is actually used. This provides a measure of the approximation to a reversible operation.

$\eta_{I I}=\frac{E x_{\min }}{E x_{t o t}}$

This definition is equivalent to the first for systems in which is possible to define a reversible process, such as a steam cycle for instance, but becomes more relevant for systems in which irreversibility is an intrinsic part of the process, as in a dryer. A similar approach has been used by Liu et al.[23]. The exergy balance equations for a control volume around the whole dryer have been derived (Appendix C). The exergy spend for overtaking the irreversibilities in the real process have been calculated from the results of the CFD simulations, while the minimum exergy demand has been calculated from a minimum exergy drying process, with a constant drying temperature of $100{ }^{\circ} \mathrm{C}$ (described in more detail in Appendix C).

\subsection{Results and discussion}

The same modeling approach used previously has been applied to this case study and the main results are provided in this section. Details of calculations regarding the energy and exergy efficiency and the complete results are reported in the supplementary work attached to the paper (Appendices B and C). Dryer specifications for the final moisture content and 
temperature of the biomass are set to $1.95 \%$ w.b. and $128^{\circ} \mathrm{C}$, so that when the remaining moisture is evaporated, during the mixing occurring between the belt and the final hopper, the temperature of the completely dry biomass will be above $105^{\circ} \mathrm{C}$ (Appendix B). The results of the CFD simulations show how the most of the moisture is evaporated in the second and third sections with a moderately low $\Delta T$ between the biomass and the steam. In the second section, the moisture is reduced from $19 \%$ w.b. to $10 \%$ w.b., then to less than $2 \%$ w.b. in the final part of the dryer where the biomass is pre-heated. The whole sets of results from the CFD simulation and Aspen model are shown in Figure 8 and in Appendix B (Table B.3). The total residence time in the dryer is about 72 minutes.

The results of the macroscale mass balance and energy balance of the dryer are reported in Figure 9. The total heat demand for the $100 \mathrm{MW}$ plant is $4220 \mathrm{~kW}$ of which around $1650 \mathrm{~kW}$ is at $140^{\circ} \mathrm{C}$ and $2570 \mathrm{~kW}$ at $165^{\circ} \mathrm{C}$. The electricity consumption is $356 \mathrm{~kW}$. However, this value is strictly dependent on the pressure losses in the heat exchangers, and therefore on the type of heat exchangers used.

The efficiency of the drying system is high since the only losses are from the evacuation stream and the heat losses along the dryer, amounting to $144 \mathrm{~kW}$ and $186 \mathrm{~kW}$ respectively. The energy efficiency of the dryer is calculated through the eq. 30 , resulting in $92.8 \%$.

$\eta_{I}=1-\frac{Q_{\text {loss }}+H_{e v a c}}{Q_{1}+Q_{2}+Q_{3}+W_{1}+W_{2}+W_{3}}$

From the CFD results, it is possible to calculate how the supplied energy is used in the dryer. As shown in Figure 10, most is spent on the evaporation of the moisture, which is later recovered as gasification steam.

The exergy analysis for a $100 \mathrm{MW}$ fuel input dryer yields that the minimum exergy demand is of $165(\mathrm{~kJ} / \mathrm{kg}$ dry biomass) while the exergy spend in the real system is $311(\mathrm{~kJ} / \mathrm{kg}$ dry biomass), leading to an exergy efficiency of $52.9 \%$. The second-law efficiency of the system is considerably higher than those of other dryers using air or steam [23], [24], [25]. This good 
result is due to the recovery of the evaporated moisture as gasification steam, and to heat transfers occurring with a moderately low temperature difference. This analysis enhances the importance of continuity between drying and pre-heating equipment and the gasifier. Cooling of the wood and condensing of the moisture after drying are not beneficial to the system, since the sensible heat cannot be recovered for any useful purpose. With a continuous drying and feeding system, heat can be used at a moderately low temperature (below $170^{\circ} \mathrm{C}$ ), both for drying and pre-heating of the streams, to recover the exergy in the evaporated moisture without condensing it and to reduce the head demand in the gasifier.

\section{Conclusions}

The present work proposes an integrated dryer and conveyor belt for woody biofuels with steam as the heat transfer medium. The design of the dryer is based on macroscopic heat and mass balance modeling in Aspen Plus, with detailed information on the drying process of the individual biomass particles supplied by computational fluid dynamics (CFD) simulations and experimental data to further improve the precision and reliability of the macroscopic model. The CFD simulation setup proposed here can be further used to optimize the dryer design, with respect to bed height, steam injection temperatures and fuel type. The presented Aspen model can be integrated in the modeling of a larger process and used to investigate the integration of the drying within a biomass plant.

Integrating the proposed technology with an indirect steam gasifier, about $0.82 \mathrm{MJ} / \mathrm{kg}$ (daf) of heat can be shifted out from the gasifier heat demand, by drying and pre-heating of the biomass and moisture, starting from $20 \%$ w.b. moisture content. Low temperature heat (below $170^{\circ} \mathrm{C}$ ) is used in the drying, and the dryer can be easily integrated within a steam cycle present in the plant or other heat sources at moderate temperature. Comparing this system to a direct feeding of wet biomass into the gasifier, more char will be available for gasification 
with the proposed design, thus boosting the yield of gas produced. The reutilization of the removed moisture as a gasification agent is the key to increasing the energy and exergy efficiency of the drying process. Steam guarantees safe inertization and pre-heating of the dry fuel, as well as a contaminant-free purging atmosphere. These advantages, in addition to a design that can be derived from existing air belt dryers, indicate that the herein proposed drying technology presents a very competitive choice for operation with indirect steam gasification units. 


\section{Appendix A}

\section{Results of thermogravimetric analysis of the wood chips}

The normalized weight loss and temperature of 19 samples of wood chips (initial moisture content $67.45 \%$ on dry basis) were recorded during temperature-programmed evaporation in a thermogravimetric analysis (TGA) (cf. Figure A.1). The wood drying experiments in the TGA were designed on the base of the procedure for oven dry moisture measurement from the Swedish standard SS 187170 [26], that prescribes a drying at $105^{\circ} \mathrm{C}$ in nitrogen for 24 hours. The wood chips were grained to a particle size smaller than $5 \mathrm{~mm}$ to feed them in the TGA in samples of $1 \mathrm{~g}$. The mass of the samples was compared to that of the wood chips before the graining to account for moisture loss during the size reduction step. The wood chip samples are first heated to $105^{\circ} \mathrm{C}$ and held at this temperature until the drying is complete (the weight loss curve levels off). After this period, the temperature is increased to $160^{\circ} \mathrm{C}$ and held constant for an hour. The nitrogen flow in the TGA is $7 \mathrm{lpm}$, more technical data about the unit used can be found at [27]. The evaporation rate during the drying phase at $105{ }^{\circ} \mathrm{C}$ was lower than $0.01 \mathrm{~g}_{\mathrm{H} 2 \mathrm{O}} / \mathrm{min}$. The average drying time of the 19 samples at was $83.5 \mathrm{~min}$ with a standard deviation of $6.2 \mathrm{~min}$.

No significant weight loss is registered after the initial drying at $105^{\circ} \mathrm{C}$, even when the temperature is raised to $160^{\circ} \mathrm{C}$. Therefore the presence of tighter bound water and the release of VOCs in this temperature range are neglected in the calculations. 


\section{Appendix B}

\section{Details of dryer integration within an indirect steam gasifier}

The layout proposed for the coupling of steam belt dryer with the feeding system of an indirect gasifier using steam is explained in Section 5 and depicted in Figure 7. In addition to the main advantages related to this integration, some other aspects can be pointed out about safety and startup procedures. In case of an unexpected shutdown of the dryer, it is possible to have a backflow of hot flammable gases from the gasifier. Emergency sealing devices will be present in the feeding system, but in the eventuality that some of the backflow gas reaches the dry biomass, a system for flushing the dryer with flue gases should be considered. The flue gases can later be evacuated though the evacuation pipe. The flue gases circuit could also be used during the startup procedure, instead of steam, and evacuated later in the same way. Furthermore, the moist air coming from the air dryer can be used in the combustor, increasing the water concentration, which results in lower carbon monoxide emissions.

One aspect must be pointed out regarding the evaporation of the last moisture left in the biomass. Wood chips have a non-spherical shape and wherever two or more particles overlay (i.e. come into close contact), a volume with low external surface is created. The remaining moisture is mostly probably located in the core of this volume, which has virtually no surface available for evaporation. As soon as the wood chips are mixed, falling into the final hopper, the remaining moisture will be evaporated, absorbing heat from the surroundings. When using the wood particle as the only heat source for evaporation, the final temperature of the completely dry wood can be coupled to the moisture content and temperature of the biomass at the end of the belt, by a simple heat balance.

$\Delta \boldsymbol{T}_{\text {wood }}=\frac{Y_{\text {final }}}{1-Y_{\text {final }}} \cdot \frac{\Delta h_{\text {evap }}}{C p_{\text {wood }}}$ 
Therefore, to pre-heat the completely dry biomass to above $105^{\circ} \mathrm{C}$, the temperature at the end of the drying belt should be above $128^{\circ} \mathrm{C}$ and the moisture content below $1.95 \%$. These data are used for design specifications of the dryer.

The methodology outlined in Section 3 is applied to design a dryer integrated within the gasification plant. The biomass bed height is varied in the three sections of the dryer to avoid steam condensation, reduce the $\Delta T$ between the biomass and the steam and pre-heat the biomass. In addition, mixing between each section reduces the effect of chip overlaying. The general assumptions about the dryer and the gasifier are reported in Table B.1.

The results from the CFD simulation have been used in the macroscopic model shown in Figure B.1. The biomass pre-heating section has been added to the previous model (Figure 3), and the moisture recovering circuit has been changed to lead the moisture into the gasifier. The power needed for compression of the moisture before injection into the gasifier is not taken into account in the dryer energy balance. The moisture evacuated together with the air in the first section is condensed and the heat can be recovered in the air dryer.

The evaporation of the remaining moisture occurs in the hopper and is modeled in the blocks "DRYER4" and "FLASH4", reducing the temperature of the wood. This moisture is assumed to be recovered in the steam circuit and is therefore available as gasification steam.

Heat losses along the dryer are taken in account in the blocks "QLOSS". For this purpose, the dryer has been approximated to a cylinder with the total length of $250 \mathrm{~m}$ and an internal diameter of $2.2 \mathrm{~m}$ (corresponding to the belt width), calculated from the residence time obtained in the CFD simulation (Table B.2). The internal walls are made of stainless steel with a conductivity of $k_{\text {wall }}=16 \mathrm{~kW} / \mathrm{m} \cdot \mathrm{K}$ and a wall thickness of $5 \mathrm{~mm}$, while the insulation is of polyurethane foam $\left(k_{\text {ins }}=0.025 \mathrm{~kW} / \mathrm{m} \cdot \mathrm{K}\right)$ with a thickness of $35 \mathrm{~cm}$. The convective heat transfer coefficient used in the calculation is $h_{\text {conv }}=7.5 \mathrm{~kW} / \mathrm{m}^{2} \mathrm{~K}$, and the external temperature 
is $20^{\circ} \mathrm{C}$. The heat loss calculated is less than $4 \%$ of the total heat supplied in the three condensers.

Table B.3 reports the results from the macroscopic energy and mass balance, the residence time and the heat losses.

When comparing these results to those of the standalone dryer, one should consider that here the initial moisture content is double that of the previous case, and thus the residence time, the heat load and the steam consumption are all increased. 


\section{Appendix C}

\section{Exergy analysis methodology}

The definition of the second law efficiency as the ratio of the minimal exergy that must be invested in the process to the exergy that is actually used, gives a measure of the approximation of the process to reversible operation.

$\eta_{I I}=\frac{E x_{\min }}{E x_{t o t}}$

This definition is particularly relevant for those processes having intrinsic irreversibility, like wood drying. The method here applied is similar to that used by Liu et al.[23].

For a control volume system, the exergy balance can be written as:

$\sum \dot{m}_{i} \psi_{i}-\sum \dot{m}_{e} \psi_{e}-\dot{E} x_{\text {destroyed }}=-\sum\left(1-\frac{T_{0}}{T_{k}}\right) Q_{k}+W$

Where $\psi$ is the specific exergy:

$\psi=\left(h-h_{0}\right)-T_{0}\left(s-s_{0}\right)$

and $m_{i}$ and $m_{e}$ are the mass flows in and out of the volume, $Q_{k}$ is the heat transferred at the temperature $T_{k}$ and $W$ the mechanical power.

The left term of equation (C.2) is the exergy spent in passing from the initial state to the final state and in overtaking all irreversibilities. It is well known that a desorption-sorption cycle has hysteresis, and therefore it is not possible, nor useful, to quantify the heat demand for a reversible drying process. In this study, the irreversibility due to the heat of desorption is therefore included in the minimum exergy demand, $E x_{\min }$, even though it is not related to any reversible process. Since the heat of desorption depends on the temperature and the moisture content (which varies with the system temperature as well), a reference drying process for the calculation of $E x_{\min }$ has to be defined.

Since the reference process is to be valid for a steam dryer at atmospheric pressure, the drying temperature has been set to $100^{\circ} \mathrm{C}$, which is the theoretical minimum drying temperature that 
avoids steam condensation. If the approach is applied to an air dryer, the temperature would be lower, since it is possible to use low exergy heat below $100^{\circ} \mathrm{C}$. The heat transfer occurs without a finite temperature difference between the biomass and the heat source, which follows the temperature of the wood along the dryer. The moist wood is heated up to $100^{\circ} \mathrm{C}$, and the moisture is evaporated along the sorption isotherm at $100^{\circ} \mathrm{C}$ to the final moisture content, then the temperature of the wood and the moisture are raised to the final values of $128^{\circ} \mathrm{C}$ and $155^{\circ} \mathrm{C}$. Figure C. 1 shows the temperature and moisture profiles in this reference process.

The heat of sorption is calculated from the sorption isotherms in Figure C. 2 using the equation (3). While the temperature of the moist wood is increased, the wood fibers reach the saturation point (point 2) and part of the moisture is released as free water. This moisture is assumed to be evaporated immediately. The correlation between the wood temperature and the fiber saturation point is commonly calculated by [14] :

$X_{f s p}=0.3-0.001(T-20)$

Where the temperature is in Celsius and $X_{f s p}$ is the moisture content at the fiber saturation point on dry basis. Figure C.2 (left) shows the evolution of the reference process along the sorption isotherm, the heat of sorption $\Delta H_{S}$ and the term $T \cdot \Delta S_{S}$ (right).

The system is pressurized from 1.01325 bar to 1.01625 bar, before the temperature is raised, and the dead state is defined as $25^{\circ} \mathrm{C}$ and 1 atm.

The minimum exergy demand for one $\mathrm{kg}$ of dry wood is:

$$
\begin{aligned}
& E x_{\min }=\int_{1}^{4}\left(C p_{\text {wood }}(x, T)-T_{0} \frac{C p_{\text {wood }}(x, T)}{T}\right)(1+x) d T+\int_{1}^{3}\left[\Delta H_{e v}+\Delta H_{s}(x)-\right. \\
& \left.T_{0}\left(\Delta S_{e v}+\Delta S_{S}(x)\right)\right] d x+\left[\left(h_{5}-h_{V s a t}\right)-T_{0}\left(s_{5}-s_{V s a t}\right)\right]\left(x_{3}-x_{1}\right)+\frac{\Delta P}{\rho_{1}} \quad \text { C.5 }
\end{aligned}
$$

Where $c_{p \text {,wood }}$ is heat capacity of the moist wood on wet basis, $\Delta H_{e v}$ is the enthalpy of evaporation of water, $\Delta S_{e v}$ the entropy of evaporation of water, $h$ and $s$ are the specific enthalpy and entropy of water, $\Delta P$ the pressure rise in the system and $\rho_{1}$ is the initial density 
of the moist wood. The four terms on the right hand side of equation C.5 represent the exergy change due to the passage of moist wood from the initial to the final state, the desorption and evaporation of water, the superheating of the evaporated moisture and the pressurization of the system.

The energy spent in the real process is calculated from the results of the CFD and Aspen simulations.

$E x_{t o t}=W_{t o t}+\frac{\left(Q_{1}+Q_{3}\right)}{\Delta H_{e v_{165 C} C}}\left(\psi_{V s a t}-\psi_{L s a t}\right)_{165 C}+\frac{Q_{2}}{\Delta H_{e v_{140 C}}}\left(\psi_{V s a t}-\psi_{L s a t}\right)_{140 C} \quad$ C.6

$W_{\text {tot }}$ includes the power of all the fans and takes into account the pressure drops in the heat exchangers, $Q_{1}, Q_{2}, Q_{3}$ are the heat loads exchanged in the three heat exchangers and account for the heat losses. The results of the exergy analysis are reported and explained in Section 5. 


\section{Acknowledgements}

Partial financing of this work by The Centre for Combustion Science and Technology

(CECOST) is gratefully acknowledged.

\section{References}

[1] K. R. Cummer and R. C. Brown, "Ancillary equipment for biomass gasification," Biomass \& Bioenergy, vol. 23, pp. 113-128, 2002.

[2] H. Holmberg and P. Ahtila, "Comparison of drying costs in biofuel drying between multi-stage and single-stage drying," Biomass \& Bioenergy, vol. 26, pp. 515-530, 2004.

[3] B. Strömberg and S. Herstad Svärd, "The fuel handbook," Värmeforsk, 2012.

[4] H. N. Li, et al., "Evaluation of a biomass drying process using waste heat from process industries: A case study," Applied Thermal Engineering, vol. 35, pp. 71-80, Mar 2012.

[5] L. Fagernas, et al., "Drying of biomass for second generation synfuel production," Biomass \& Bioenergy, vol. 34, pp. 1267-1277, Sep 2010.

[6] A. G. McDonald, et al., "Air emission from timber drying: High temperature drying and re-drying of CCA treated timber," Holz als Roh - und Werkstoff, vol. 62, pp. 291302, // 2004.

[7] W. A. Amos, "Report on Biomass Drying Technology," NREL - National Renewable Energy Laboratory NREL/TP-570-25885, 1998.

[8] R. W. Fredrikson, "Utilization of Wood waste as fuel for rotary and flash tube wood dryer operation.," in Biomass fuel drying conference, Minnesota, 1984.

[9] R. Jirjis, "Storage and drying of wood fuel," Biomass \& Bioenergy, vol. 9, pp. 181190, 1995.

[10] Wilén, C., Moilanen, A., Rautalin, A., Torrent, J., Conde, E., Lödel, R., Carlson, D., Timmers, P., Brehm, K. (1999) Safe handling of renewable fuels and fuel mixtures, Espoo: Technical Research Centre of Finland, VTT Publications 394, 117 pp. + app. 8 pp.

[11] J. S. Tumuluru, et al., "Review on biomass torrefaction process and product properties and design of moving bed torrefaction system model development," 2011, pp. 58865924.

[12] C. Pfeifer, et al., "Comparison of dual fluidized bed steam gasification of biomass with and without selective transport of CO2," Chemical Engineering Science, vol. 64, pp. 5073-5083, 12/1/ 2009.

[13] C. Skaar, Wood-water relations, Springer Berlin Heidelberg, 1988.

[14] J. F. Siau, Transport Processes in Wodd. New York: Springer 1984.

[15] A. TenWolde, et al., "Thermal properties of wood and wood panels products for use in buildings," OAK ridge national laboratory 1988.

[16] A. T. Inc., "Getting started modeling processes with Solids," July 20102012.

[17] G. Towler and R. K. Sinnott, Chemical Engineering Design: Elsevier, 2012.

[18] S. Hermansson and H. Thunman, "CFD modelling of bed shrinkage and channelling in fixed-bed combustion," Combustion and Flame, vol. 158, pp. 988-999, May 2011.

[19] H. Ström and H. Thunman, "CFD simulations of biofuel bed conversion: A submodel for the drying and devolatilization of thermally thick wood particles," Combustion and Flame, vol. 160, pp. 417-431, 2// 2013. 
[20] N. Wakao and S. Kaguei, Heat and Mass Transfer in Packed Beds, Gordon \& Breach, London, 1982.

[21] S. S. Institute, "Biofuels and peat - Determination of total moisture content," ed: Swedish Standard Institute, 1990.

[22] M. Corporation. (2010). Kuvo Belt Dryer. Available: http://www.metso.com/MP/marketing/Vault2MP.nsf/BYWID/WID-090218-2256E27B91/\$File/WHDU_R_2080_040-02.pdf?OpenElement

[23] Y. P. Liu, et al., "Exergy Analysis of Biomass Drying Based on Self-Heat Recuperation Technology and Its Application to Industry: a Simulation and Experimental Study," Industrial \& Engineering Chemistry Research, vol. 51, pp. 9997-10007, Aug 12012.

[24] M. Aghbashlo, et al., "A review on exergy analysis of drying processes and systems," Renewable and Sustainable Energy Reviews, vol. 22, pp. 1-22, 2013.

[25] C. Coskun, et al., "Energy and exergy analyses of an industrial wood chips drying process," International journal of low carbon technologies, vol. 4, pp. 224-229, 2009.

[26] R. Mehrabian, S. Zahirovic, R. Scharler, I. Obernberger, S. Kleditzsch, S. Wirtz, et al., "A CFD model for thermal conversion of thermally thick biomass particles," Fuel Processing Technology, vol. 95, pp. 96-108, 3// 2012.

[27] K. W. Ragland, D. J. Aerts, and A. J. Baker, "Properties of wood for combustion analysis," Bioresource Technology, vol. 37, pp. 161-168, // 1991.

[28] G. V., V. H., and G. Š, "Selected properties of European beech," Journal of Forest Science, vol. 54, pp. 418-425, 2008.

[29] H. R., "Variation of thermal properties of beech wood in the radial direction with moisture content and density," presented at the the 6th IUFRO Symposium Wood Structure and Properties' 10', Podbansk, Slovakia, 2010.

[30] K. Zhang and C. You, "Numerical simulation of lignite drying in a packed moving bed dryer," Fuel Processing Technology, vol. 110, pp. 122-132, 6// 2013.

[31] Y. B. Yang, Y. R. Goh, R. Zakaria, V. Nasserzadeh, and J. Swithenbank, "Mathematical modeling of MSW incineration on a travelling bed," Waste Management, vol. 22, pp. 369-380, 2002.

[32] C. Bruch, B. Peters, and T. Nussbaumer, "Modelling wood combustion under fixed bed conditions," Fuel, vol. 82, pp. 729-738, 2003.

[33] P. Lerman and O. Wennberg, "Experimental method for designing a biomass bed dryer," Biomass and Bioenergy, vol. 35, Supplement 1, pp. S31-S39, 10// 2011. 


\section{Figure captions}

\section{Figure 1}

Illustration of the proposed drying system

\section{Figure 2}

Schematic illustration of the design of the integrated dryer and conveyor belt

\section{Figure 3}

Aspen Plus flow-sheet of the dryer

\section{Figure 4}

Computational domain for the CFD simulations

\section{Figure 5}

CFD simulation results: temperature profiles

\section{Figure 6}

CFD simulation results: average moisture content of the biomass particles as a function of time

\section{Figure 7}

Integration of the steam belt dryer in an indirect gasification system operating with steam

\section{Figure 8}


Temperatures and moisture profiles in the indirect gasifier case study

\section{Figure 9}

Mass and energy balance of the dryer in the indirect gasification case study

\section{Figure 10}

Energy share in the dryer: utilization (left) and supply (right)

\section{Figure A.1}

Normalized weight loss and temperature of 19 samples of wood chips (initial moisture content $67.45 \%$ on dry basis) during thermogravimetric analysis

\section{Figure B.1}

Aspen model of the dryer for integration with an indirect steam gasifier

\section{Figure C.1}

Temperature and moisture profile in the reference drying process

\section{Figure C.2}

Sorption isotherms, with the reference drying process (left), and the $\Delta H_{s}$ and $T \cdot \Delta S_{s}$ terms for the sorbed water 
Table 1 - Overall inputs and biomass composition.

\begin{tabular}{|c|c|c|c|c|c|}
\hline \multicolumn{3}{|c|}{ Steam dryer - overall design parameters } & \multicolumn{3}{|c|}{$\begin{array}{l}\text { As received biomass proximate analysis (wood } \\
\text { chips) }\end{array}$} \\
\hline Initial moisture & $\%$ & 10 & Moisture & $\%$ & 50 \\
\hline Final moisture & $\%$ & 4 & Char & weight-\% & 18.4 \\
\hline Initial temperature & ${ }^{\circ} \mathrm{C}$ & 25 & Volatiles & weight-\% & 81 \\
\hline $\begin{array}{l}\text { Pressure drop over } \\
\text { biomass bed and belt }\end{array}$ & $\mathrm{Pa}$ & 300 & Ash & weight-\% & 0.6 \\
\hline
\end{tabular}


Table 2 - CFD simulation results: Residence time, steam and heat load for different final moisture contents.

\begin{tabular}{|c|c|c|c|c|c|c|c|}
\hline \multirow[b]{2}{*}{ final moisture } & \multicolumn{3}{|c|}{ Section 1} & \multicolumn{4}{|c|}{ Total } \\
\hline & $\begin{array}{c}t \\
(s)\end{array}$ & $\begin{array}{c}\text { Steam } \\
\text { (kg / kg dry } \\
\text { biomass) }\end{array}$ & $\begin{array}{c}\text { Heat } \\
\text { (kJ/kg dry } \\
\text { biomass) } \\
\end{array}$ & $\begin{array}{c}\tau \\
(s)\end{array}$ & $\begin{array}{c}\tau \\
(\min )\end{array}$ & $\begin{array}{c}\text { Steam } \\
\text { (kg / kg dry } \\
\text { biomass) }\end{array}$ & $\begin{array}{c}\text { Heat } \\
\text { (kJ/kg dry } \\
\text { biomass) }\end{array}$ \\
\hline 4\% w.b. & 393 & 2.55 & 151 & 3180 & 53 & 12.6 & 331 \\
\hline $5 \%$ w.b. & 393 & 2.55 & 151 & 2670 & 44.5 & 10.9 & 304 \\
\hline $6 \%$ w.b. & 393 & 2.55 & 151 & 2190 & 36.5 & 9.4 & 277 \\
\hline 7\% w.b. & 393 & 2.55 & 151 & 1720 & 29 & 7.8 & 250 \\
\hline
\end{tabular}

Initial moisture $10 \%$ w.b. 
Table 3 - Belt width and belt speed in the two sections of the dryer for different total length of the dryer. Final moisture content $4 \%$ w.b., section length ratio (section $2 /$ section 1$)=3.54$.

\begin{tabular}{l|c|c|c}
\hline $\begin{array}{l}\text { Total length } \\
{[\mathrm{m}]}\end{array}$ & $\begin{array}{c}\text { Width } \\
{[\mathrm{m}]}\end{array}$ & $\begin{array}{c}\text { Speed B1 } \\
{[\mathrm{cm} / \mathrm{s}]}\end{array}$ & $\begin{array}{c}\text { Speed B2 } \\
{[\mathrm{cm} / \mathrm{s}]}\end{array}$ \\
\hline 100 & 2.9 & 5.6 & 2.8 \\
\hline 150 & 1.9 & 8.4 & 4.2 \\
200 & 1.4 & 11.2 & 5.6 \\
\hline
\end{tabular}


Table 4 - Inputs for macroscopic model.

\begin{tabular}{|c|c|c|c|c|c|}
\hline \multicolumn{6}{|c|}{ Aspen model inputs from CFD simulation } \\
\hline $\begin{array}{l}\text { Moisture content at the } \\
\text { switch }\end{array}$ & \% w.b. & 9.56 & Final moisture content & \% w.b. & 4 \\
\hline $\begin{array}{l}\text { Biomass average } \\
\text { temperature at the switch }\end{array}$ & ${ }^{\circ} \mathrm{C}$ & 101 & $\begin{array}{l}\text { Final biomass average } \\
\text { temperature }\end{array}$ & ${ }^{\circ} \mathrm{C}$ & 108 \\
\hline Steam recirculated section 1 & $\begin{array}{l}\mathrm{kg} / \mathrm{kg} \text { dry } \\
\text { biomass }\end{array}$ & 2.55 & Steam recirculated section 2 & $\begin{array}{l}\mathrm{kg} / \mathrm{kg} \text { dry } \\
\text { biomass }\end{array}$ & 10.01 \\
\hline Heat load section 1 & $\begin{array}{l}\mathrm{kJ} / \mathrm{kg} \text { dry } \\
\text { biomass }\end{array}$ & 151 & Heat load section 2 & $\begin{array}{l}\mathrm{kJ} / \mathrm{kg} \text { dry } \\
\text { biomass }\end{array}$ & 180 \\
\hline Pressure drop steam HE1 & bar & 0.01 & Pressure drop steam HE2 & bar & 0.01 \\
\hline \multicolumn{6}{|c|}{ Aspen model inputs from $100 \mathrm{MW}$ plant design } \\
\hline Heat losses section 1 & $\begin{array}{l}\mathrm{kJ} / \mathrm{kg} \text { dry } \\
\text { biomass }\end{array}$ & 3.32 & Heat losses section 2 & $\begin{array}{l}\mathrm{kJ} / \mathrm{kg} \text { dry } \\
\text { biomass }\end{array}$ & 9.65 \\
\hline
\end{tabular}


Table 5 - Energy balance results of the macroscopic model-100 MW fuel input.

\begin{tabular}{|c|c|c|c|c|c|c|c|c|c|c|c|}
\hline \multicolumn{3}{|c|}{$\begin{array}{l}\text { Heat exchanger } \\
\text { section } 1\end{array}$} & \multicolumn{3}{|c|}{$\begin{array}{l}\text { Heat exchanger } \\
\text { section } 2\end{array}$} & \multicolumn{3}{|c|}{$\begin{array}{l}\text { Moisture } \\
\text { Condenser }\end{array}$} & \multicolumn{3}{|c|}{$\begin{array}{l}\text { Electricity } \\
\text { consumption }\end{array}$} \\
\hline Heat load & $\mathrm{kW}$ & 773 & Heat load & $\mathrm{kW}$ & 810 & Heat load & $\mathrm{kW}$ & 883 & Fan 1 & $\mathrm{~kW}$ & 43 \\
\hline $\begin{array}{l}\text { Steam } \\
\text { flow }\end{array}$ & $\mathrm{kg} / \mathrm{s}$ & 13.8 & $\begin{array}{l}\text { Steam } \\
\text { flow }\end{array}$ & $\mathrm{kg} / \mathrm{s}$ & 51 & $\begin{array}{l}\text { Steam } \\
\text { flow }\end{array}$ & $\mathrm{kg} / \mathrm{s}$ & 0.35 & Fan 2 & $\mathrm{~kW}$ & 164 \\
\hline Temp. in & ${ }^{\circ} \mathrm{C}$ & 120 & Temp. in & ${ }^{\circ} \mathrm{C}$ & 110 & Temp. in & ${ }^{\circ} \mathrm{C}$ & 112 & & & \\
\hline Temp. out & ${ }^{\circ} \mathrm{C}$ & 150 & Temp. out & ${ }^{\circ} \mathrm{C}$ & 120 & Temp. out & ${ }^{\circ} \mathrm{C}$ & 50 & & & \\
\hline
\end{tabular}

Final moisture content $4 \% w . b$. 
Table B.1 - General assumptions for the indirect gasification case study.

\begin{tabular}{lll}
\hline Biomass type & - & wood chips (Table 1) \\
\hline Biomass flow (dry ash free) & $\mathrm{kg} / \mathrm{s}$ & 5.4 \\
Initial moisture & weight $\%$ & 20 \\
final moisture & weight $\%$ & $<2 \%$ \\
\hline Biomass pre-heating & $\mathrm{C}$ & $128^{\circ} \mathrm{C}$ \\
\hline Gasification steam pre-heating & $\mathrm{C}$ & $155^{\circ} \mathrm{C}$ \\
\hline MP steam & - & $7 \mathrm{bar}, \quad \mathrm{T}_{\mathrm{sat}} 165^{\circ} \mathrm{C}$ \\
\hline LP steam & - & $3.6 \mathrm{bar}, \mathrm{T}_{\mathrm{sat}} 140^{\circ} \mathrm{C}$ \\
\hline Design length & $\mathrm{m}$ & 250 \\
\hline Bed height section 1 and 3 & $\mathrm{m}$ & 0.1 \\
\hline Bed height section 2 & $\mathrm{m}$ & 0.2 \\
\hline
\end{tabular}


Table B.2 - Design of the belt for different total lengths.

\begin{tabular}{cccc}
\hline $\begin{array}{c}\text { Belt Length } \\
(\mathbf{m})\end{array}$ & $\begin{array}{c}\text { Belt Width } \\
(\mathbf{m})\end{array}$ & $\begin{array}{c}\text { Speed section } \\
\mathbf{1} \text { and } \mathbf{3}(\mathbf{c m} / \mathbf{s})\end{array}$ & $\begin{array}{c}\text { Speed section 2 } \\
(\mathbf{c m} / \mathbf{s})\end{array}$ \\
\hline 150 & 3.65 & 5 & 2.5 \\
200 & 2.75 & 6.5 & 3.25 \\
250 & 2.20 & 8 & 4 \\
300 & 1.85 & 10 & 5 \\
\hline
\end{tabular}


Table B.3 - Aspen model results in the indirect gasifier case study.

\begin{tabular}{|c|c|c|c|c|}
\hline \multicolumn{2}{|c|}{ Aspen model inputs from CFD simulation } & \multirow{2}{*}{$\begin{array}{c}\text { Section } 1 \\
19.35\end{array}$} & \multirow{2}{*}{$\begin{array}{c}\text { Section } 2 \\
10.3\end{array}$} & \multirow{2}{*}{$\begin{array}{c}\text { Section } 3 \\
1.95\end{array}$} \\
\hline $\begin{array}{l}\text { Moisture content at the end of } \\
\text { the section }\end{array}$ & $\%$ & & & \\
\hline $\begin{array}{l}\text { Biomass average temperature } \\
\text { the end of the section }\end{array}$ & ${ }^{\circ} \mathrm{C}$ & 93 & 107 & 128 \\
\hline Steam recirculated in the section & $\begin{array}{l}\mathrm{kg} / \mathrm{kg} \text { dry } \\
\text { biomass }\end{array}$ & 2.85 & 9.11 & 7.16 \\
\hline Heat load in the section & $\begin{array}{l}\mathrm{kJ} / \mathrm{kg} \text { dry } \\
\text { biomass }\end{array}$ & 176 & 308 & 317 \\
\hline $\begin{array}{l}\text { Pressure drop steam in } \\
\text { condensers }\end{array}$ & bar & 0.01 & 0.01 & 0.01 \\
\hline Residence time in the section & $\mathrm{s}$ & 465 & 2545 & 1320 \\
\hline \multicolumn{5}{|c|}{ Aspen model inputs from $100 \mathrm{MW}$ plant design } \\
\hline Heat losses in the section & $\begin{array}{l}\mathrm{kJ} / \mathrm{kg} \text { dry } \\
\text { biomass }\end{array}$ & 2.5 & 24 & 8 \\
\hline
\end{tabular}

Initial moisture content $20 \%$, initial biomass temperature $25^{\circ} \mathrm{C}$ 